\title{
Preference for delay-associated cues: Cognitive dissonance?
}

\author{
L. CHARLES WARD and JAMES C. VARBLE \\ Murray State University, Murray, Ky. 42071
}

Eighteen albino rats were given 96 trials in a runway during which delay-box cues were differentially paired with $2-, 10-$, and 30 -sec reinforcement delays. The animals then received 18 paired-comparison trials, in a $\mathrm{Y}$-maze, where they were exposed to the three possible pairings of the delay-associated cues. It was found that the animals chose the 2 -sec cue significantly more often when paired with either the 15- or 30-sec delay. There was no difference in the frequency of choice for the 10 - and 30 -sec pairing. Results were discussed with reference to Festinger's "cognitive dissonance" theory, which predicts a preference for cues associated with longer delays.

A number of studies have demonstrated that increasing delays of reinforcement increase resistance to extinction (Renner, 1964). Festinger (1961) has suggested that this increased resistance to extinction is due to an "extra preference" developed for delay-associated cues during acquisition. This preference, which serves to reduce cognitive dissonance, is assumed to increase with increasing delays. On the other hand, Spence (1960) has pointed out that delay of reinforcement is analogous to experimental extinction and as such is an elicitor of frustration. According to this position, cues present during the delay should take on aversive properties due to their pairing with the elicitation of frustration. Thus, Festinger's cognitive dissonance theory predicts that organisms should have a preference for delay-associated cues, whereas from a frustration hypothesis it might be expected that organisms will tend to avoid cues associated with long delays. The present experiment was designed to test the prediction made by "cognitive dissonance" theory by allowing the organism to choose between pairs of cues which had previously been associated with 12-, 15-, and 30-sec delays.

\section{SUBJECTS}

The Ss were 18 experimentally naive male albino rats of the Sprague-Dawley strain. They were approximately 120 days old at the beginning of the experiment.

$$
\text { APPARATUS }
$$

$A$ runway and a $Y$-shaped choice apparatus (Y-maze) were used in the experiment. Both were constructed of plywood and were covered with screen-mesh wire. The runway consisted of a startbox, $15 \times 19 \mathrm{~cm}$, an alleyway, $15 \times 90 \mathrm{~cm}$, and a goalbox, $22 \times 25 \mathrm{~cm}$, and could be fitted with any one of three delay boxes, $25 \times 25 \mathrm{~cm}$. The delay boxes were painted black, white, or gray and were placed between the end of the alley and the goalbox. The startbox, alleyway, and goalbox were unpainted. Guillotine doors separated the four sections of the runway. The Y-maze was constructed so that an unpainted stem $(15 \times 30 \mathrm{~cm})$ could be fitted with any two of three arms. The arms were $15 \times 45 \mathrm{~cm}$ and were black, white, or gray. Each of the arms could be placed in either the left or right position on the stem. The design of the Y-maze was such that both arms were clearly visible to an animal at the choice point.

\section{PROCEDURE}

The experiment was conducted in three phases-runway pretraining, runway training, and transfer tests in the Y-maze.

Five days prior to pretraining, the Ss were placed on a 23-h food-deprivation schedule, which was continued throughout the experiment. During a 10-day pretraining period, the Ss were adapted to the runway by being placed in the startbox and allowed to explore with all doors open and to obtain food in the goalbox. The delay boxes were not used in this phase of the experiment.

The Ss ran six trials per day for 16 days during runway training. On each trial, $\mathrm{S}$ was placed in the startbox and allowed to run down the alleyway. When $S$ entered the delay box, the door closed behind him and he was held for the appropriate delay interval. At the end of the delay, the door to the goalbox was opened and he was given $1 \mathrm{~min}$ to eat. All Ss were run two trials a day under a $2-, 10-$, and $30-$ sec delay of reinforcement. The sequence of delays for each $\mathrm{S}$ on each day was randomly selected. The 18 rats were divided into three equal groups, with each group receiving a different combination of pairings of delay with delay-box cues. Across Ss, the cues, black, white, and gray, were used equally often with each delay. Thus, training consisted of exposing the Ss to three delay cues which were differentially paired with $2 \cdot, 15-$, and 30-sec delays.

During transfer, a paired-comparison procedure was followed in which the Ss were exposed to the three possible pairings of delay cues used in acquisition. Each $S$ ran six trials a day for 4 days in the Y-maze. A trial consisted of placing $S$ at the base of the stem in the $Y$ and allowing him to make a left or right choice. An approach of $15 \mathrm{~cm}$ or more into the left or right arm was taken to be a choice. S was immediately removed following a choice. On all 4 days of transfer, the Ss were given two trials on each of the three pairings of delay cues, black, white, or gray. The sequence of trials was determined randomly. On the second daily trial for each cue pair, the position (left-right) of the cues was reversed.

RESULTS AND DISCUSSION

The frequencies of choice of the cues for each pairing were as follows: The 2-sec cue was chosen 65 of 108 times when paired with the 10 -sec cue and 75 of 108 times when paired with the 30 -sec cue. The 10 -sec cue was chosen 54 of 108 times when paired with the 30 -sec cue. Analysis of these results using the normal approximation to the binomial distribution indicated that the $2-\mathrm{sec}$ cue was chosen significantly more often when paired with either the $10-\sec (p<.05)$ or $30-\sec (p<.0001)$ cue, but there were no differences for the 10- and 30-sec pairing.

These results may be taken as evidence against Festinger's (1961) "cognitive dissonance" interpretation as applied to the delay of reward situation. The results indicate that animals do not develop a preference for cues associated with delay. It appears that, in fact, they either develop a preference (tendency to approach) for cues associated with shorter delays or an aversion (tendency to avoid) for cues associated with the long delays. The latter interpretation is consistent with the hypothesis that frustration is elicited during longer delays and becomes conditioned to the cues in the delay box.

REFERENCES

FESTINGER, L. The psychological effects of insufficient rewards. American Psychologist, 1961, 16, 1-11.

RENNER, K. E. Delay of reinforcement: A historical review. Psychological Bulletin, 1964, 61, 341-361.

SPENCE, K. W. The roles of reinforcement and non-reinforcement in simple learning. In K. W. Spence (Ed.), Behavior theory and learning. Englewood Cliffs, N.J: Prentice-Hall, 1960 . 